\title{
Numerical Simulation of Fluid Structure Interaction Between Wave and Steel Pipe Pile Platform in Deep Water
}

\author{
Wenyue Yan* and Fengwu Lv \\ Department of Building Engineering, College of Civil Engineering, Tongji University,1239 Siping Road, Shanghai 200092, P.R. \\ China \\ ${ }^{*}$ Corresponding author
}

\begin{abstract}
The $k-\varepsilon$ turbulence model and the VOF method of moving interface tracking have been used to generate the wave. By two-way iterative method, the fluid structure interaction between wave and steel pipe pile platform has also been simulated numerically by using ANSYS Workbench. Taking the construction platform in deep waters of the Yangtze River Estuary as an example, the stress and deformation characteristics of the steel pipe pile platform under wave forces are analyzed in detail. As a resulted, it is suggested the platform piles should be arranged regularly and the connected node design of the platform structure should be strengthened to ensure the safety.
\end{abstract}

Keywords-VOF method; the two-way coupling; wave; pile foundation platform

\section{INTRODUCTION}

The trend of ocean development is towards deep waters. People have been building many structures in deep water in recent years, such as oil drilling platforms, offshore wind power, ports and bridges crossing seas and rivers. The wave plays an important role in safety, cost and life of the construction in the deep water [1]. In practical engineering, most of small piles are in the form of pile groups, so the interaction between pile group and wave makes the wave field more complicated. With the development of engineering in deep water, the research on the coupling effect of wave and structure has attracted more attention.

It's a tendency to study fluid structure coupling by means of numerical simulation, as a result of rapid development in calculation. Xiaoling Zhu [2] used ANSYS and CFX to simulate two-way fluid-structure interaction for tandem double piles and wave field. Integrating with the simulation results of the single pile, the maximum equivalent stress of both was compared. Chen Yang [3] simulated the interaction between waves and two vertical and two horizontal piles. Xinxin Lei [4] studied hydrodynamic characteristics of the five piles structure under the wave action, by the means of physical model test and numerical simulation. Shengrong Zuo [5] simulated the role of circular piers by combing the action of waves and uniform flow and analyzed the response of the piers. Shan Zhong [6] studied the simulation analysis of the wave surface coupling, the dorsal surface coupling and the whole coupling respectively.
Documents above mainly focus on numerical simulation of waves and fluid structure coupling between wave and pile, but few have studied the coupling effect between wave and platform structure. In this paper, a two-way coupling of wave and structure platform is simulated by using ANSYS Workbench, and the structure platform has nine piles with space angle and different pile spacing. The coupling effect between the steel pipe pile platform and the wave is analyzed, which provides a reference for future engineering practice.

\section{MODEL AND CONTROL EQUATIONS}

\section{A. Equation of Fluid Solid Coupled System Field}

Fluid is assumed to be free viscous, compressible and small perturbations, and fluid free surface is small fluctuation; and solid is assumed to be linear elastic. The finite element analysis method of the system constituted with the two ideal materials above has two types: Displacement-Displacement form and Displacement-Potentials form. As the DisplacementPotentials form is more efficient, it is highly used in engineering now. It means that the displacement $u_{i}$ is used as basic unknown quantity in the equation of solid domain, while the flow field pressure $p$ is used as basic unknown quantity in the equation of fluid domain. The corresponding finite element expression format is called displacement-pressure $\left(u_{i}, p\right)$ scheme for fluid solid coupling analysis [7].

1) Fluid field

a) Fluid field equation

$p_{, i i}-\frac{1}{c_{o}^{2}} \ddot{p}=0$

where $p$ is fluid pressure, $C_{o}$ is sound velocity in fluid.

b) Fluid boundary conditions

Rigid fixed boundary: 
$\frac{\partial p}{\partial n_{f}}=0$

Free surface:

$\frac{\partial p}{\partial z}+\frac{1}{g} \ddot{p}=0$

2) Solid field

a) Solid field equation

$$
\sigma_{i j, j}+f_{i}=\rho_{s} \ddot{u}_{i}
$$

where $\sigma_{i j}$ is solid stress component, $u$ is solid displacement component, $f_{i}$ is solid volume force component, $\rho_{s}$ is solid mass density.

\section{b) Solid doundary conditions}

Force boundary:

$$
\sigma_{i j} n_{s j}=\overline{T_{i}}
$$

Displacement boundary:

$$
u_{i}=\overline{u_{i}}
$$

where $\bar{T}_{i}$ is known surface force component on solid, $\bar{u}_{i}$ is known displacement components on solids.

3) Compatibility conditions on the fluid solid coupling interface

a) Kinematic condition: The normal velocity of the fluid solid interface should be continuous, which means

$v_{f n}=v_{f} \cdot n_{f}=v_{s} \cdot n_{f}=-v_{s} \cdot n_{s}=v_{s n}$

Using the equation of motion of the fluid the kinematic condition can be rewritten as

$$
\frac{\partial p}{\partial n_{f}}+\rho_{f} \ddot{u} \cdot n_{f}=0
$$

where $u$ is solid displacement vector, $\rho_{f}$ is fluid mass density. b) Dynamitic condition: Normal stress should be continuous on the interface of fluid solid interface, i.e.

$$
\sigma_{i j} n_{s j}=\tau_{i j} n_{f j}=-\tau_{i j} n_{s j}
$$

Where $\tau_{i j}$ is component of fluid stress tensor. For free viscous fluid, $\tau_{i j}$ can be represented as

$$
\tau_{i j}=-p \delta_{i j}
$$

Taking Eq. (10) into Eq. (9), then

$$
\sigma_{i j} n_{s j}=p n_{s j}(11)
$$

\section{B. Turbulence Model}

For the fluid structure coupling problem in deep water, considering the fluid as turbulent fluid, the additional turbulent equation is needed. In this paper, the standard $k-\varepsilon$ turbulence model is used.

Equation of fluctuating kinetic energy $k$ is:

$$
\begin{aligned}
& \frac{\partial(\rho k)}{\partial t}+\nabla \cdot(\rho \mathbf{u} k)=\nabla \cdot\left[\left(\mu+\frac{\mu_{t}}{\sigma_{k}}\right) \nabla k\right]+P_{k}-\rho \varepsilon+S_{k} \\
& P_{k} \text { is defined by }
\end{aligned}
$$

$$
P_{k}=\mu_{t} \nabla \boldsymbol{u} \cdot\left(\nabla \boldsymbol{u}+\nabla \boldsymbol{u}^{T}\right)-\frac{2}{3} \nabla \cdot \boldsymbol{u}\left(3 \mu_{t} \nabla \cdot \boldsymbol{u}+\rho k\right)
$$

Where $\mu_{t}$ is eddy viscosity,

$$
\mu_{t}=C_{\mu} \rho \frac{k^{2}}{\varepsilon}
$$

Equation of turbulent dissipation rate $\varepsilon$ is:

$\frac{\partial(\rho \varepsilon)}{\partial t}+\nabla \cdot(\rho \mathbf{u} \varepsilon)=\nabla \cdot\left[\left(\mu+\frac{\mu_{t}}{\sigma_{\varepsilon}}\right) \nabla \varepsilon\right]+\frac{\varepsilon}{k}\left(C_{\varepsilon 1} P_{k}-C_{\varepsilon 2} \rho \varepsilon\right)+S_{\varepsilon}$

Here, $S$ is custom source term.

In $k-\varepsilon$ turbulence model, $C_{\mu}, \sigma_{k}, \sigma_{\varepsilon}, C_{\varepsilon 1}, C_{\varepsilon 2}$ are empirical constants, whose values are given by [8]. 


\section{Wave Theory}

The linear wave equation is used for the wave numerical simulation in this paper:

$$
\eta=\frac{H}{2} \cos (k x-\omega t)
$$

The velocity equation of wave motion is:

$$
\left\{\begin{array}{l}
u=\frac{\partial \varphi}{\partial x}=\frac{k H g}{2 \omega} \frac{\operatorname{ch} k(h+z)}{\operatorname{ch} k h} \cos (k x-\omega t) \\
w=\frac{\partial \varphi}{\partial z}=\frac{k H g}{2 \omega} \frac{\operatorname{sh} k(h+z)}{\operatorname{ch} k h} \sin (k x-\omega t)
\end{array}\right.
$$

The pressure of the linear wave is as follows:

$$
p=-\rho g z-\rho g \frac{H}{2} \frac{\operatorname{ch} k(h+z)}{\operatorname{ch} k z} \cos (k x-\omega t)
$$

In the above Eqs, $k$ is the number of waves per second, and $k=\frac{2 \pi}{\lambda}, \lambda$ is the wavelength; $\omega$ is the circle frequency of wave; $H$ is the wave height;

$h$ is the distance of the fixed boundary to the water surface; $g$ is the gravity acceleration.

\section{VOF Method}

The volume of fluid (VOF) is a free interface tracking method, and it has advantages in reducing the amount of calculation, as well as ensuring the quality of conservation. What's more, it can deal with large deformation of the free surface without any numerical dissipation. Therefore it is used to trace wavefront.

In the VOF method, the volume fraction function $\phi_{q}$ is introduced, which represents the ratio of the phase q fluid volume to the whole unit volume. $\phi_{q}=1$ indicates that all of the units are $q$ phase material, $\phi_{q}=0$ indicates that $q$ phase material is empty in the units, $0<\phi_{q}<1$ indicates that the unit is an interface unit.

Wave in the deep water is gas-liquid two-phase, so the governing equations are as follows:

$$
\frac{\partial \phi_{q}}{\partial t}+\frac{\partial\left(u \phi_{q}\right)}{\partial x}+\frac{\partial\left(v \phi_{q}\right)}{\partial y}=0
$$

$$
\sum_{q=1}^{2} \phi_{q}=1
$$

\section{NumERICAL SOLUTION METHOD}

The partial differential equations of fluid structure coupling shown above are quite complicated. It's difficult to get the analytical solution of these equations. However, it is common to use numerical analysis method by computer to solve differential equations with a given boundary condition. Commonly used numerical analysis methods are Finite Difference Method (FDM), Finite Element Method (FEM) and Finite Volume Method (FVM). In this paper FEM in ANSYS Structure is used to solve the solid equations, while FVM in ANSYS CFX is used to solve the fluid equations.

Displacement-Pressure form is used as the finite element analysis model in this paper. The solid transmits its displacement to the fluid, considering the nodal displacement as boundary condition, the equation that uses the pressure of the flow field as the unknown variable can be solved. And then the flow transmits the boundary pressure to the solid, which considers nodal displacement as the unknown quantity of equations. After solving the nodal displacement, it is transmitted to the fluid, which will become the boundary condition of fluid field, and then circulate step by step until convergence.

This paper use ANSYS Workbench to carry out numerical simulation of fluid solid coupling. Workbench use ANSYS CFX and ANSYS Structure, respectively, to solve the fluid equation and solid equation in the same step, and then use MFX procedure of ANSYS to exchange the data on the fluid solid coupling surface. The solid and fluid fields are calculated according to the updated boundary conditions. The specific implementation thought is shown as FIGURE I .

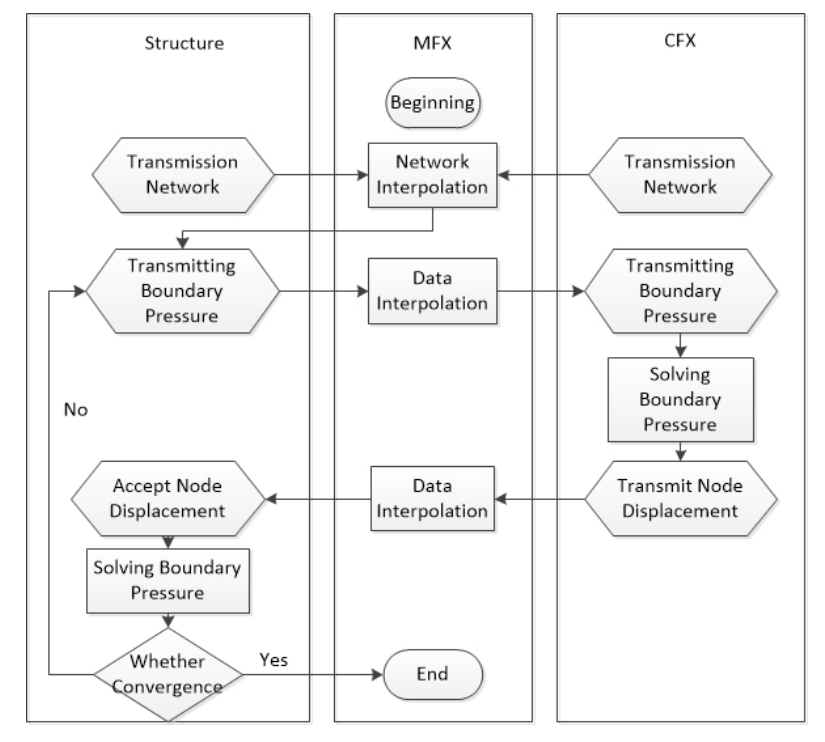

FIGURE I. THE REALIZATION OF FLUID STRUCTURE COUPLING 
The number of iteration is controlled by the convergence accuracy. And it is taken as the convergence control criterion when RMS is less than 1e-4 in this paper.

\section{WAVE NUMERICAL SIMULATION}

\section{A. Wave Parameter Setting}

The data for setting wave parameter is from Xu Liu Jing hydrological observation station in the Yangtze River Estuary. So the wave height is $0.7 \mathrm{~m}$, the wavelength is $16 \mathrm{~m}$, the depth is $25 \mathrm{~m}$. According to experience, the tank size is $100 \mathrm{~m} * 14 \mathrm{~m}$ * $30 \mathrm{~m}$, and the static water depth is $25 \mathrm{~m}$.

The hexahedral automatic meshing is used to mesh the numerical tank. The size control is used in a wave height range from static water, As shown in FIGURE II. The number of grid cells is 822500 , and the number of nodes is 3397379 , and the average quality of the grid is 0.84 .

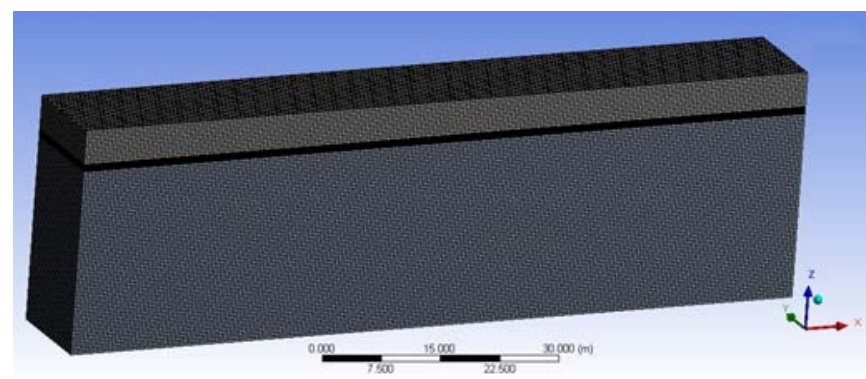

FIGURE II. TANK MESHING

The boundary setting is shown in FIGURE III. In order to avoid backflow, the opening boundary condition is used in both entrance and exit.

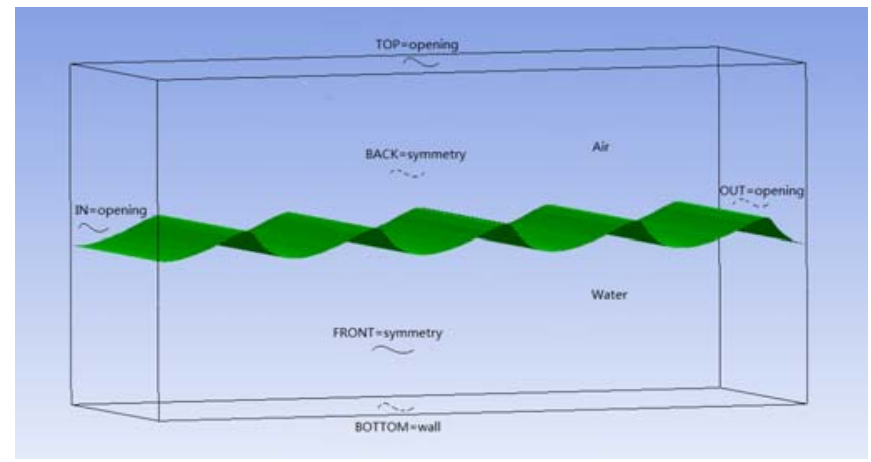

FIGURE III. TANK BOUNDARY

\section{B. Wave Validation}

The wave tank should be verified before the simulation of two-way coupling between wave and steel pipe pile platform. The simulation value is compared with the theoretical calculation of the wave position. FIGURE IV shows the simulation wave and theoretical wave at $2.4 \mathrm{~s}$. The computer simulated curve depicts similar trend as that of the theoretical curve. The maximum difference is $0.28 \%$ and the average difference is $0.009 \%$.

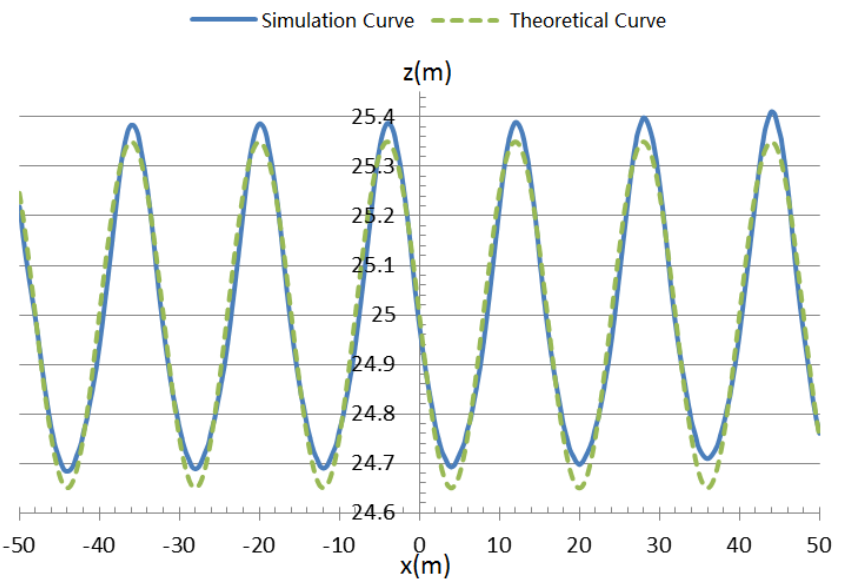

FIGURE IV. COMPARISON BETWEEN SIMULATION AND THEORY OF WAVEFRONT POSITION $(\mathrm{T}=2.4 \mathrm{~S})$

\section{CASE ANALYSIS}

A pier construction platform of a long-span cable bridge in the Yangtze River Estuary is selected as an example to simulate the two-way coupling between wave and steel pipe pile platform in deep water.

The platform is a complex and irregular platform, whose length along the wave is $24 \sim 27 \mathrm{~m}$, width is $12 \mathrm{~m}$, and it is composed by 9 steel pipe piles, whose diameter is $1.4 \mathrm{~m}$ and thickness is $16 \mathrm{~mm}$. What's more there are space angles between wave and five of the nine piles, and the piles spacing are different.

Steel pipe piles are integrated together by two parallel laterals in upper and lower. The upper laterals are located on the top of the pile, and the elevation spacing between the upper and lower laterals is $3 \mathrm{~m}$. The steel pipe of $\phi 800(\delta=$ $10 \mathrm{~mm})$ is used for upper laterals, and the steel pipe of $\phi 400$ $(\delta=10 \mathrm{~mm})$ is used for lower laterals.

Hydrological conditions are the same as the section IV. The pile (platform) top is $5 \mathrm{~m}$ higher than the static water.

In order to simplify the calculation, the laterals are simplified as a rectangular solid beam with equivalent stiffness, and the steel pipe piles are fixed on the river bed. Platform structure model is shown in FIGURE V.

The finite element mesh of the platform is automatically divided according to the requirement of fluid solid coupling data transmission. The number of grid cells is 61522 , and the number of nodes is 182370 . And solid185 is used as finite element.

FIGURE VI shows the stress-time curves of bottom of pipes B, E, $\mathrm{H}$ between $3 \sim 5 \mathrm{~s}$.

Table 1 shows the maximum displacement of the platform and the maximum stress of the platform component in one wave period. 


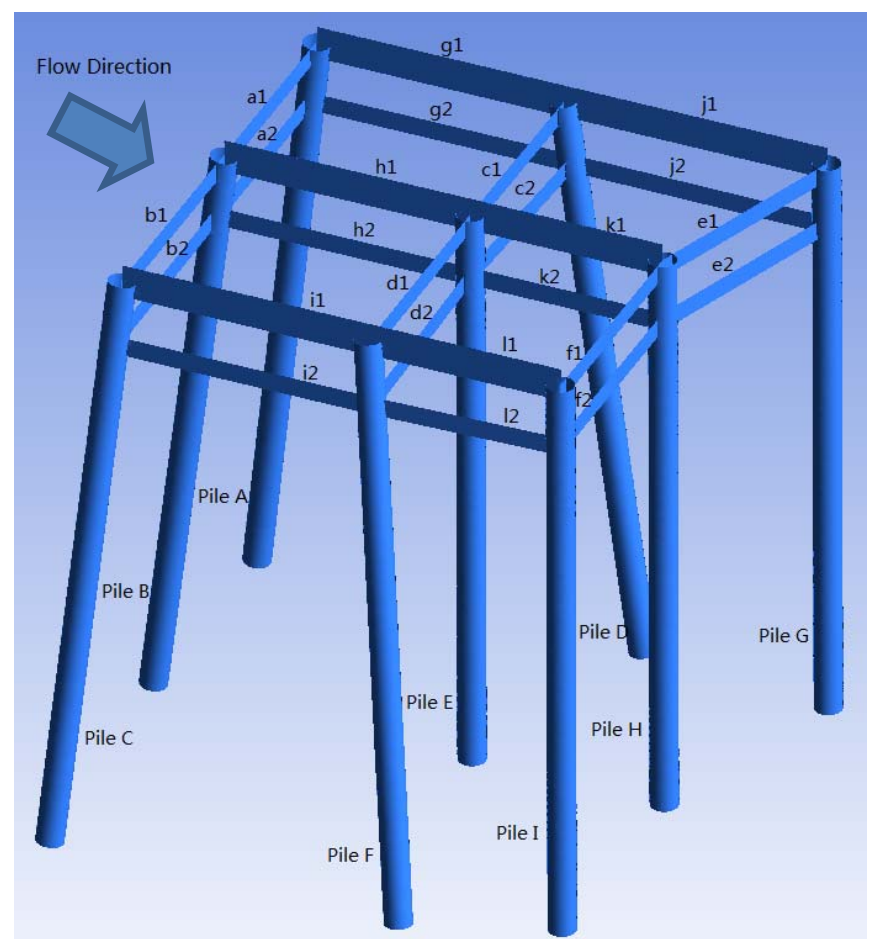

FIGURE V. CONSTRUCTION PLATFORM MODELING

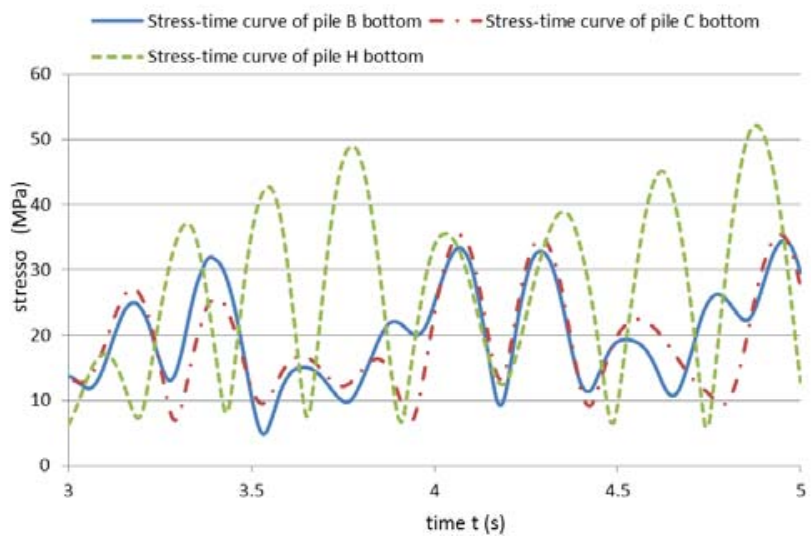

FIGURE VI. STRESS-TIME CURVES OF PILE BOTTOM

TABLE I. MAXIMUM DISPLACEMENT OF PLATFORM, MAXIMUM STRESS OF COMPONENT

\begin{tabular}{|c|c|c|c|c|c|}
\hline $\begin{array}{c}\text { Time } \\
\mathbf{t} / \mathbf{T}\end{array}$ & $\begin{array}{c}\text { Maximum } \\
\text { horizontal } \\
\text { displacement } \\
\text { of platform } \\
\mathbf{u} / \mathbf{m m}\end{array}$ & $\begin{array}{c}\text { maximum } \\
\text { stress of } \\
\text { laterals } \\
\mathbf{\sigma} / \mathbf{M P a}\end{array}$ & $\begin{array}{c}\text { maximum } \\
\text { stress } \\
\text { position } \\
\text { of laterals }\end{array}$ & $\begin{array}{c}\text { Maximum } \\
\text { stress of } \\
\text { steel pipe } \\
\text { pile } \\
\text { o /MPa }\end{array}$ & $\begin{array}{c}\text { Maximum } \\
\text { stress } \\
\text { position } \\
\text { of steel } \\
\text { pipe piles }\end{array}$ \\
\hline $\mathbf{0}$ & 31.08 & 86.9 & $\begin{array}{c}\text { lateral i1\& } \\
\text { top of Pile } \\
\text { C }\end{array}$ & 52.1 & $\begin{array}{c}\text { Bottom of } \\
\text { pile I }\end{array}$ \\
\hline $\mathbf{1 / 8}$ & 35.86 & 91.2 & $\begin{array}{c}\text { lateral i1\& } \\
\text { top of Pile } \\
\text { C }\end{array}$ & 36.6 & $\begin{array}{c}\text { Bottom of } \\
\text { pile B,C }\end{array}$ \\
\hline $\mathbf{1 / 4}$ & 41.97 & 112.0 & $\begin{array}{c}\text { lateral } \\
\text { b1\& top } \\
\text { of Pile B }\end{array}$ & 56.0 & $\begin{array}{c}\text { Bottom of } \\
\text { pile C,F,I }\end{array}$ \\
\hline $\mathbf{3 / 8}$ & 46.22 & 140.0 & lateral & 69.8 & Bottom of \\
\hline
\end{tabular}

\begin{tabular}{|c|c|c|c|c|c|}
\hline $\mathbf{1}$ & & & $\begin{array}{c}\text { a1,g1\& } \\
\text { top of Pile } \\
\text { A }\end{array}$ & pile D \\
\hline $\mathbf{5 / 8}$ & 78.08 & 127.0 & $\begin{array}{c}\text { lateral } \\
\text { g1\& top } \\
\text { of Pile A }\end{array}$ & 50.9 & $\begin{array}{c}\text { Bottom of } \\
\text { pile C,F,I }\end{array}$ \\
\hline $\mathbf{3 / 4}$ & 22.18 & 98.6 & $\begin{array}{c}\text { lateral } \\
\text { b1\& top } \\
\text { of Pile B }\end{array}$ & 80.0 & $\begin{array}{c}\text { Bottom of } \\
\text { bile G,H,I } \\
\text { of Pile B }\end{array}$ \\
\hline $\mathbf{7 / 8}$ & 85.31 & 160.0 & 29.0 & $\begin{array}{c}\text { Bottom of } \\
\text { pile } \\
\text { B,E,H,I }\end{array}$ \\
\hline
\end{tabular}

As can be seen from table 1 , the values and positions of the maximum stress and the maximum displacement of the platform are both changed with the wave propagation.

The variation range of the maximum stress is 86.9 $\mathrm{MPa} 178 \mathrm{MPa}$, and the variation range of the maximum displacement is $22.18 \mathrm{~mm} \sim 85.31 \mathrm{~mm}$.

The calculation results show that the connecting points between the piles and the laterals are stress concentration points, so the connection should be strengthened in the design of platform. In order to improve the working performance of the platform, it is recommended to settle piles regularly, and strengthen the stiffness of the front and back row piles. stresstime curves of pile bottom

\section{CONCLUSIONS}

- It's feasible to use VOF method and $k-\varepsilon$ turbulence model for numerical simulation of wave. The simulation wave curve coincides well with the theoretical curve.

- Through the numerical simulation of the two-way coupling interaction between wave and the working platform, the results of the nine-pile platform under wave action are analyzed. The results demonstrate that the structural integrity of the platform has a great influence on the stress of the steel pipe pile. The maximum stress is concentrated at the joint of the steel pipe piles and the laterals, especially concentrated at the joint of laterals and the first row piles or the inclined piles.

- According to the analysis of the calculation results, it is suggested that the platform piles should be arranged regularly, and the connected node design of the platform structure should be strengthened to ensure the safety.

- ANSYS Workbench can be used to simulate the twoway fluid structure coupling between platform and wave. In this paper, the computation time of the example is about 120 hours, so it can be seen that the fluid solid two way coupling computation is quite costly. 


\section{REFERENCES}

[1] Yuanfang Liu, Xiufen Huang, Jia Hao Lin. Dynamic Safety Checking of Fixed Jacket Platform [J]. Computational Structural Mechanics and Applications, 1990,7 (3) :73-83.

[2] Xiaoling Zhu. A Study on Fluid-solid Coupling Simulation of Offshore Platform Pile Foundation Structure [D]. North China Electric Power University, 2014.

[3] Chen Yang. Numerical Simulation of wave forces on small-diameter cylinders using three-dimension Unsteady Reynolds Equation Model [D] Tianjin University, 2006.

[4] Xinxin Lei. Research on Hydrodynamic Performance of Pile Array Under Wave Action[D]. Dalian University of Technology, 2013.

[5] Shengrong Zuo. Research on Wave Response of Deepwater Pier [D]. Wuhan University of Technology, 2013.

[6] Shan Zhong. The Dynamic Response Analysis of Pier Under The Action of Wave Based on Fluid-Solid Coupling [D]. Chongqing Jiaotong University, 2013

[7] Yanrong Zhu. Ocean Engineering Wave Mechanics [M]. The first edition. Tianjin: Tianjin University press, 1998.

[8] Zhengxian Liu, Baojun Song, Chuangang Gu. Numerical Study of High Order Anisotropic $k-\varepsilon$ Models and Its Coefficients. Journal of Engineering Thermal Physics, 1996. 17 (Suppl): 31-34. 